\title{
Adrenal hemorrhage presenting as a scrotal hematoma in the newborn. A case report
}

\author{
Erbu Yarci, M.D. ${ }^{a}$, Sema Arayici, M.D. ${ }^{a}$, Fatma Nur Sari, M.D. ${ }^{a}$, Fuat Emre Canpolat, M.D. ${ }^{a}$, \\ Nurdan Uras, M.D. ${ }^{a}$ and Ugur Dilmen, M.D. ${ }^{a, b}$
}

\begin{abstract}
Neonatal adrenal hemorrhage is uncommon. It is present in $0,2 \%$ of newborns. Ten percent of the cases occur bilaterally. It can be associated with birth trauma, large birth weight, or neonatal course complicated by hypoxia and asphyxia, hypotension, or coagulopathy. Scrotal hematoma is an extremely rare manifestation of NAH. Most patients present scrotal swelling with bluish discolouration. Scrotal swelling with/without bluish discoloration in newborns may result from different causes. We report an unusual case of neonatal adrenal hemorrage secondary to perinatal asphyxia, associated with SH. Neonatal adrenal hemorrhage and scrotal hematoma were diagnosed by ultrasonography and treated by conservative treatment, avoiding unnecessary surgical exploration.

Key words: asphyxia neonatorum, adrenal gland diseases, hemorrhage, scrotal hematocele.
\end{abstract}

http:/ /dx.doi.org/10.5546/aap.2015.eng.e161

\section{INTRODUCTION}

Scrotal swelling with/without bluish discoloration in newborns may result from different causes including hydrocele, inguinal hernia, meconium peritonitis, orchitis, testicular tumors, testicular trauma or torsion. ${ }^{1}$ Adrenal hemorrhage resulting from perinatal asphyxia, trauma, sepsis and coagulation abnormalities can also cause scrotal hematoma. ${ }^{2}$ Rare cases of idipoathic etiology were reported. We report an unusual case of neonatal adrenal hemorrage (NAH) secondary to perinatal asphyxia, associated with scrotal hematoma(SH).

\section{CASE REPORT}

A $3400 \mathrm{~g}$ male, with vaginal delivery complicated by shoulder dystosia, required

a. Division of Neonatology, Zekai Tahir Burak Maternity Teaching Hospital.

b. Department of Pediatrics, Yıldırım Beyazıt University School of Medicine.

Ankara, Turkey.

E-mail Address:

Erbu Yarci, MD: erbuyarci@yahoo.com

Funding: None.

Conflict of interest: None.

Received: 11-25-2014

Accepted: 1-26-2015 entubation at birth and had evidence of multisystem hypoxic ischaemic insult. On sixth day of life, a bluish discolouration and swelling appeared in the right scrotum (Figure 1). Scrotal ultrasound showed a right scrotal haematoma with normal testis (Figure 2). Abdominal ultrasound revealed bilateral suprarenal cystic masses suggesting adrenal haemorrhage. Blood count showed: hemoglobin $16.2 \mathrm{~g} / \mathrm{dl}$, hematocrit $51 \%$, white blood cells $25000 / \mathrm{mm}^{3}$, and platelets $269000 / \mathrm{mm}^{3}$. Prothrombin time and activated partial thromboplastin time were normal. The infant was managed conservatively with a plan to monitor the mass with regular ultrasonographic examinations. Follow-up ultrasound showed decrease in the size of adrenal haemorrhage with complete resolution. Test results showed no abnormality in the hypothalamic-adrenal axis and adrenal functions.

FIGURE 1. Swelling and bluish discoloration of the right groin and hemiscrotum

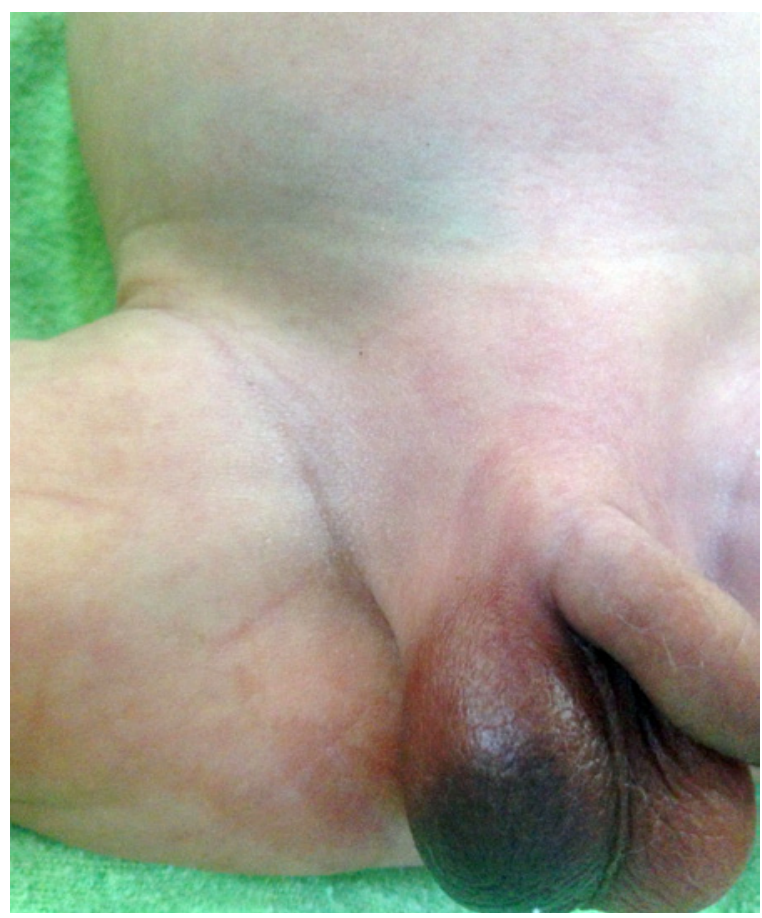




\section{DISCUSSION}

$\mathrm{NAH}$ is uncommon; it presents in $0,2 \%$ of newborns and $0,05-0,14 \%$ of autopsy cases. Ten percent of the cases occur bilaterally. ${ }^{2}$ It usually occurs at birth or during the first days following birth. ${ }^{3}$ In the newborn, the adrenal gland is very large and vulnerable to vascular damage. ${ }^{4}$ It can be associated with birth trauma, large birth weight, or neonatal course complicated by hypoxia and asphyxia, hypotension, or coagulopathy. It can also occur spontaneously. ${ }^{5}$

Clinical manifestations of $\mathrm{NAH}$ are variable, depending on the degree and rate of hemorrhage, as well as the amount of adrenal cortex compromised by hemorrhage. ${ }^{2,6}$ The most frequent manifestations are anemia, abdominal mass, jaundice, and rarely scrotal swelling with skin discoloration. ${ }^{5,7}$ If bleeding is moderate, blood remains in the adrenal capsule. A large amount of blood can cause the rupture into the peritoneal cavity or retroperitoneal space. Blood reaches the scrotum through a patent processus vaginalis or by dissection of the tissue of the retroperitoneum. . $, 5,8^{2}$

$\mathrm{SH}$ is an extremely rare manifestation of NAH. Most patients present scrotal swelling with bluish discolouration. Scrotal swelling with/without bluish discoloration in newborns is unusual

FIGURE 2. Abdominal ultrasonography showing blood collection around right and left adrenal glands, which was enlarged and heterogeneous, consistent with bilateral adrenal hemorrhage

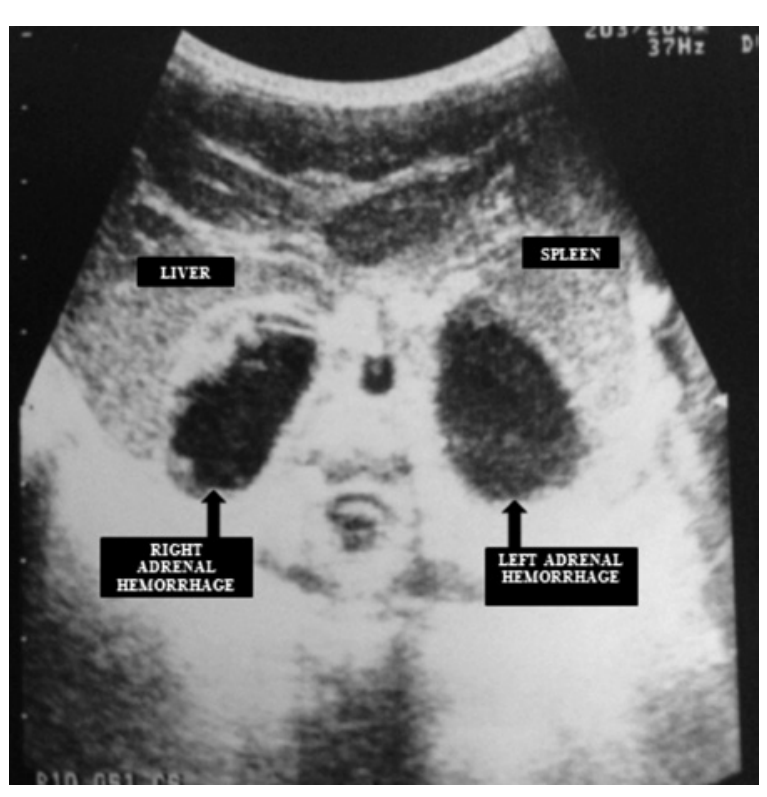

and may result from different causes including hydrocele, testicular trauma with testicular edema, inguinal hernia, congenital tumors and meconium peritonitis. Acute and subacute torsion of the spermatic cord should also be considered. ${ }^{9}$ Several authors recommend considering an acute scrotal incident as testis torsion to provide rapid surgical exploration improving testicular salvage. ${ }^{10,11}$ Some of the cases reported with $\mathrm{NAH}$ and $\mathrm{SH}$ received unnecessary operation. It is important to avoid unnecessary surgical exploration in the differential diagnosis of scrotal swelling and bluish discoloration in newborns. ${ }^{12}$

In our case, sonographic evaluation of the scrotum showed a right scrotal haematoma with normal testis and normal Doppler ultrasound examination. Abdominal ultrasound evaluation showed the presence of bilateral suprarenal cystic masses suggesting adrenal haemorrhage. Ultrasonographic evaluation of both testes and abdomen is necessary for differential diagnosis. ${ }^{13-15}$

Of the 29 cases of NAH and $\mathrm{SH}$ reported in the literature, nine received unnecessary surgical exploration. In all the cases managed surgically, the decision to perform a surgical intervention was based only on the physical examination leading to the suspect of testicular torsion. ${ }^{14}$

Surgical intervention showed a normal testis in all cases. Postoperative abdominal ultrasound revealed ipsilateral adrenal hemorrhage in all the cases. Conservatively managment based on physician's previous experiences and the suspection of NAH as the cause of scrotal swelling, avoided unnecessary surgical exploration. ${ }^{12}$

In conclusion, adrenal hemorrhage may present as scrotal swelling mimicking an acute scrotum. The differential diagnosis between this condition and other causes of scrotal swelling is based on clinical history, physical examination, and ultrasound examination of both testes and abdomen. This conservative management allows unnecessary surgical exploration of the scrotum.

\section{REFERENCES}

1. Gonçalves R, Abuabara A, Abuabara RF, Feron CA.Scrotal hematoma as a sign of adrenal hemorrhage in newborns. Sao Paulo Med J 2011;129(2):113-5.

2. Bergami G, Malena S, Di Mario M, Fariello G. [Echography in the follow-up of neonatal adrenal hemorrhage. The presentation of 14 cases]. Radiol Med 1990;79(5):474-8. Italian.

3. Navarro OM, Daneman A. Congenital and Neonatal Conditions. In: Coley BD, ed. Caffey's pediatric diagnostic 
imaging. $12^{\text {th }}$ ed. Philadelphia: Elsevier Saunders; 2013:12749.

4. Amoury RA, Barth GW, Hall RT, Rhodes PG, et al. Scrotal ecchymosis: sign of intraperitoneal hemorrhage in the newborn. South Med J 1982;75(12):1471-5.

5. Duman N, Oren H, Gülcan H, Kumral A, et al. Scrotal hematoma due to neonatal adrenal hemorrhage. Pediatrics Int 2004;46(3):360-2.

6. Khuri FJ, Alton DJ, Hardy BE, Cook GT, et al. Adrenal hemorrhage in neonates: report of 5 cases and review of the literature. J Urol 1980;124(5):684-7.

7. Liu KW, Ku KW, Cheung KL, Chan YL. Acute scrotal swelling: a sign of neonatal adrenal haemorrhage. J Paediatr Child Health 1994;30(4):368-9.

8. Miele V, Galluzzo M, Patti G, Mazzoni G, et al. Scrotal hematoma due to neonatal adrenal hemorrhage: the value of ultrasonography in avoiding unnecessary surgery. Pediatric Radiol 1997;27(8):672-4.

9. Adorisio O,Mattei R, Ciardini E, CentonzeN, at al. Neonatal adrenal hemorrhage mimicking an acute scrotum. J Perinatol 2007;27(2):130-2.

10. Das S, Singer A. Controversies of perinatal torsion of the spermatic cord: a review, survey and recommendations. J Urol 1990;143(2):--3.

11. Al-Salem AH. Intra-uterine testicular torsion: early diagnosis and treatment. BJU Int 1999;83(9):1023-5.

12. Lai LJ, Chen LM, Chu PY, Tseng MH, et al. Neonatal adrenal hemorrhage associated with scrotal hematoma: an unusual case report and literature review. Pediatr Neonatol 2012;53(3):210-2.

13. Ibanez Godoy I, Mora Navarro D, Delgado Rioja MA, Losada Martinez A, et al. Hematoma escrotal unilateral. An Pediatr (Barc) 2004;60(5):477-8.

14. Anding R, Fastnacht-Urban F, Walz PH. ['Acute scrotum' in the neonate. Adrenal haemorrhage as cause]. Urologe A 2000;39(1):48-51. German.

15. Giacoia GP, Cravens JD. Neonatal adrenal hemorrhage presenting as scrotal hematoma. J Urol 1990;143(3):567-8. 